\title{
A simple method for the estimation of global solar radiation from sunshine hours and other meteorological parameters
}

\author{
A.Q. Jakhrani ${ }^{1}$, A. K. Othman ${ }^{1}$, A. R. H. Rigit ${ }^{1}$ and S. R. Samo ${ }^{2}$ \\ ${ }^{1}$ Faculty of Engineering, Universiti Malaysia Sarawak, 94300, Kota Samarahan, Sarawak, Malaysia \\ ${ }^{2}$ Department of Energy \& Environment Engineering, Quaid-e-Awam University of Engineering, Science \& Technology, \\ Nawabshah, Sindh, Pakistan \\ E-mail: aqunimas@hotmail.com
}

\begin{abstract}
Estimation of solar radiation is considered as the most important parameter for the design and development of various solar energy systems. But, the availability of the required data is very scarce and often not readily accessible. The foremost objective of the present study was to evaluate the various models for the estimation of monthly average global solar radiation from bright sunshine hours and other meteorological parameters at four locations namely Sri Aman, Sibu, Bintulu and Limbang in the Sarawak State. For this purpose, six different solar radiation models, such as Angstrom, Glover, Tasdemirglu, Bahel, Hargreaves and Sayigh, have been investigated. The computed values are compared and assessed, but no relationships of results were found among selected models and with measured values of the nearest location. Hence, a simple and more flexible model is introduced based on the input data of bright sunshine hours, relative humidity and maximum temperature, for the prediction of available global solar radiation on a horizontal surface. The required data for the suggested model is usually available in the most meteorological sites. The proposed model demonstrated acceptable results, and statistically displayed lower RMSE and MBE as compared to the examined models. It could be a good estimator for predicting the global solar radiation in coastal and humid areas.
\end{abstract}

Keywords- bright sunshine hours; empirical models; global solar radiation; meteorological parameters; solar energy systems

\section{INTRODUCTION}

Solar energy occupies one of the most important places among various alternative energy sources. An accurate knowledge of solar radiation availability at a particular geographical location is of vital importance for the development of solar energy systems and for the estimation of their efficiencies and output $[1,2]$. The familiarity of solar radiation data is a pre-requisite for the modeling and design of all photovoltaic and solar thermal power schemes [3, 4]. Architects, agriculturalists, air conditioning engineers and energy designers require the knowledge of solar radiation data for the proper design and operation of engineering projects [5-8]. The information of radiation is also valuable for atmospheric energy-balance, climatology and pollution studies, analysis of the thermal load on buildings, solar energy collecting systems and economic viability of methods [9-12]. The network of stations measuring the solar radiation data is sparse in many developing countries, and only few stations are well equipped for the measurement of the daily solar radiation on a consistent basis [13]. Measured monthly average values of daily irradiation, are usually the best source of information and provide the starting point for many calculations. The usefulness of long-term monthly averages of daily radiation can be understood from the fact that at a particular location these averages are relatively constant, so that past values can be used to estimate future ones. When the solar radiation data is unavailable, then there is one possibility to get reasonable radiation estimates from commonly available meteorological parameters, such as sunshine hours, relative humidity, maximum and minimum temperatures, and cloud cover of that geographic location [14]. For this purpose, in the past, numerous empirical correlations have been developed in order to estimate the solar radiation around the world. There are several models available, which correlate the global radiation to other climatic parameters such as sunshine hours, relative humidity and maximum temperature. The most commonly used parameter for estimating global solar radiation is sunshine duration. The hours of bright sunshine are measured by Campbell-Stokes sunshine recorder. The intensity of sun radiation burns a mark on the paper, whenever it is above a critical level. The lengths of the burned portions of the paper provide an index of the duration of bright sunshine. The measurements are somehow uncertain, because of its interpretation which constitutes burned part. The burned fraction does not respond to low levels of radiation early and late in the day [15]. However, the sunshine recorder is more reliable than visual estimation of cloud covers, and its data is also widely available in most of places around the globe [16]. The value of recorded sunshine hours needs to be converted through mathematical models for the determination of solar radiation level in the area. The basic and fundamental empirical model was proposed by Angstrom in 1924. Most of authors modified the Angstrom model for estimating solar radiation data at their places of interest. Since, some researchers proposed quadratic models; a few authors suggested linear logarithmic models, whereas, the others presented power trigonometric models. In this study, six empirical models were examined for computing global solar radiation at various places of Sarawak State namely; Sri 